\title{
We all love playing in the sand! Using sand play therapy in critical reflection with students in practice placement
}

\section{Debbie Amas ${ }^{1}$}

Summary: This paper introduces a creative therapeutic technique used in Projective Play Therapy called sand play therapy that I evolved in my work with students on placement to help them reflect on practice. In this paper I describe my experience of facilitating a sand tray exercise I devised as part of a group seminar programme for BA Social Work students to help them both explore their practice in placement and examine Learning Outcomes linked with knowledge from their module learning. Finally I discuss the evaluation undertaken with participating students about the usefulness of the exercise as an intuitive reflective tool.

Keywords:sand play; projective play therapy; practice learning; social work; critical reflection

1. Tutor. Anglia Ruskin University / independent practice teacher/trainer

Address for Correspondence:, Faculty of Health and Social Care, Anglia Ruskin University, The Webb Building, East Road, Cambridge, CB1 1PT.

D.A.Amas@anglia.ac.uk

6 Journal of Practice Teaching \& Learning 7(2) 2006-07, pp.6-24. ( 2007 Whiting E Birch Ltd 


\section{Introduction}

I was first introduced to the sand play technique in the mid nineties when I worked as a team leader of social workers carrying out Direct Work and Life Story work with children and young people. Our team were fortunate to have a qualified social worker who was also a trained art therapist. He taught us how sand play could be used therapeutically with children and young people in a Direct Work setting by facilitating a direct experience of the technique for our team. We were intrigued as our colleague took each one of us through what he called a projective play exercise. The work, or play, happened in a wooden box full of play sand surrounded by amazing small toys, objects, jewels, candles and jugs of water. One by one he encouraged us to build a landscape representing our world and to explore it narratively with each other. On that day our colleague introduced us to a powerful and flexible therapeutic tool which we later came to use to reflect on dynamics and power relationships during difficulties within our team and in the wider organisation. At the time I was also a Practice Teacher and had a student for whom the sand play technique became a useful tool that helped her to construct an understanding of power relationships and team dynamics in a tangible way in the sand tray. Since that time I am always prompted to use the sand tray exercise in my practice with individual student/practitioners. In the two seminars where I conducted the sand play technique I found that it can be a powerful and thoughtful group work tool that provokes deep learning, particularly in considering anti oppressive/ anti discriminatory practice, ethics and values and use/ abuse/ misuse of power.

Deep learning processes are essential for students if they are to develop critically reflective practice acknowledged as an essential pre requisite for practicing safely with service users:

... because of the responsibilities that social workers and probations officers carry, and the influence and impact they can have on the lives of vulnerable people, that as well as being skilled and knowledgeable that they treat people with respect and are honest, trustworthy and reliable. They must be self aware and critically reflective and their practice must be founded on, informed by and capable, of being judged against a clear value base. (General Social Care Council, 2006, p.6)

7 Journal of Practice Teaching \& Learning 7 (2) 2006-07, pp.6-24. ( 2007 Whiting \& Birch Ltd 
The development of reflective practice in Higher Education mainly influenced by Donald A. Schon throughout the 1970s and 1980s has led to a number of taught techniques that help students critically reflect in spaces where practice and knowledge meet (Kolb, 1984; Gibbs, 1985). The space may be facilitated in practice tutorials, seminars, small group teaching, as well as in consultation and mentoring. Models of small group teaching and one to one tutorials with focussed exercises allow opportunities for students to practice reflexivity that takes them out of routine learning with the inherent intention of identifying and deepening knowledge. Thus students should become explicit parties to a contextualised course design that embeds opportunities for breadth in learning. (Brockbank and McGill, 2000).

In the social work degree students need to reflect not only on cultural, organisational, socio-political, procedural and governmental frameworks and theoretical contexts of their work, but also on personal values, all of which impact on the lives of people who use the services where they undertake their Practice Learning Opportunities. Students need to develop confidence as practitioners if they are to develop skills that allow them to challenge, advocate, work in partnership with and collaborate across professions in complex circumstances in the best interests of service users.

In developing the sand tray technique to work with student/ practitioners my aim is to bring the material world of practice to a learning space in a unique way, giving students a powerful opportunity to reflect on a landscape they make intuitively about their practice in a sand play exercise. My vision in developing the idea is to use creative practice in reflection in order to more deeply ground their knowledge.

Inevitably there has been some discussion about the conditions needed so that critical reflection can inspire confidence in social work practice. In reflecting, students are asked to consider uncomfortable aspects of their work which may provoke anxiety for a variety of reasons. Firstly the practitioner/student is aware that practice is governed by a framework of competence within a driver of performance management and social work modernisation that can act as a barrier, or as Baldwin (2004) states, 'threat' to critical reflection. Secondly, student/practitioners may unconsciously, or consciously, reframe practice narratives for a knowing audience within a framework of professional understanding or cultural 'fit', possibly seeing the scrutiny of practice as a personal criticism of

8 Journal of Practice Teaching \& Learning 7(2) 2006-07, pp.6-24. ( 2007 Whiting \& Birch Ltd 
their work. (Taylor, 2006). Yipp (2005) identifies processes in critical reflection that by their nature will relate to psycho-dynamic theories in the examination of relationships, including transference and countertransference. Further, practice may be examined in an atmosphere of comparative analysis where the practitioner measures or compares their performance with others:

That means that the individual social worker is evaluating not only his or her performance but also his or her personality, professional competence and identity. (Yip, 2006, p.780).

Clearly, the student/practitioner is vulnerable within the critically reflective process. Care is needed to ensure that the conditions set up to examine practice increases self determination and instills robust professionalism. The projective play process facilitated in the sand tray exercise, providing it is set up correctly, is a creative space for the student/practitioner to explore practice. The factors that threaten good reflective practice remain present and need to be acknowledged within the context of the exercise. That is, the exercise cannot take away the power of assessment, management frameworks, possible personal anxiety and oppression in working environments. What it offers is a creative and potentially powerful way of examining what is going on. The making of the sand landscape helps student/practitioners construct an understanding and potentially resolve issues or find a deeper meanings and contexts for their work. The following brief history of projective play therapy which includes sand tray therapy, demonstrates how the technique is removed from traditional interpretive or psychoanalytic perspectives towards a solution focussed model. This not only models good practice for student/practitioners, but provides them with an empowerment tool that can be used in Direct Work.

\section{History of projective play processes and sand play therapy}

Sand play therapy was developed by Margaret Lowenfeld who began her pioneering work in what she termed 'projective play therapies' with children as early as 1937 when she realised that childs play was

9 Journal of Practice Teaching \& Learning 7(2) 2006-07, pp. 6-24. () 2007 Whiting \& Birch Ltd 
not an accident but as an essential function of childhood basically concerned with the adaptive process ... continues throughout life ... and affects man's ability to survive in his physical universe ... and social environments. (1967, p.2)

The unique feature of Lowenfeld's therapy with children was the value base in the child's exploration of their own world without using psychotherapeutic interpretation in a conventional sense. Her view was that the worlds she facilitated in the creation of landscapes in sand trays, and other play therapeutic techniques she developed, belonged wholly to the child who could explore that world within a safe and trusting relationship with an adult in any way they wished, much as they would in natural play:

The primary attribute of the therapist was that he/she was a trustworthy, child friendly adult who was genuinely interested in providing the child with the means to express and to understand him/herself. Thus, in sand play she helped children enter and explore their Worlds. She felt that the World, not the interpretive therapist, needed to confront its maker. In fact, when she asked children to introduce their Worlds and their characters to her, she validated their capacity to create, to experience, and to revise their own meanings. Whenever she honoured the child as the keeper of the story-of-meaning, she learned to speak the language of the child rather than expecting the child to speak the language of the therapist. (De Domenico, 2002)

The sand tray exercise was one of many techniques developed by Lowenfeld in what she termed projective play therapy to encourage children to explore themselves and their world through play with the intention of facilitating potential solutions, or moving through issues that impacted on their lives, such as loss, change, trauma and bereavement. The ongoing development of play therapy through to current times has demonstrated the importance of observing play and finding ways to open up a space for children that is therapeutic, safe, engaging and fun, but that also helps them to think about their own solutions to situations they decide how to define and narrate for themselves.

Lowenfeld mainly considered her work as a tool for children and young people. However, projective play techniques were soon recognised as a tool that could be used with adults. Jungian and Gestalt therapists

10 Journal of Practice Teaching E Learning 7(2) 2006-07, pp.6-24. (C 2007 Whiting E Birch Ltd 
saw the potential of the sand tray technique for bringing unconscious material into the conscious world (Stevens 2004). Like many play and creative arts therapy tools sand play has gone on to prove itself. It can work effectively with those who have faced deep traumas, such as war, disaster and terrorism with children and adults. In my view, within a broad spectrum of people who use services from individuals, families and groups and within a consultation or supervision processes for health and social care professionals, the sand tray technique offers an opportunity for anyone explore their world with new eyes.

\section{Using the sand tray exercise}

Before commencing with my description of the exercise I used with my BA Social Work Seminar Groups I would like to emphasise the experiential nature of the tool and the importance of working with the sand tray prior to using it with others. Where the Practice Teacher is part of the organisation providing the Practice Learning Opportunity particular care will be needed in considering some of the issues surrounding the safety of critical reflection already discussed. At the beginning of this article I described how a team member trained in therapeutic arts facilitated an experience of a sand tray exercise. I find working intimately with the sand tray to be a very powerful learning within itself, acquainting me not only with its strength as a cathartic and solution focussed tool, but also to the very sound principles of a non interpretive approach:

Sand play evokes very deep realities. It cuts across many familial and cultural taboos as it activates the deep, primordial integrative forces of the psyche. Whether an educator, a trained expressive, ar or play therapist or whether an accomplished verbal, behavioural, or cognitive clinician, each sand play facilitator needs to use the sand tray for his/her own personal growth and development before integrating the tool into the play- and consultation room.' (De Domenico, 1995)

Another crucial element in introducing the technique is to acknowledge that it is a therapeutic tool. The use of any therapeutic model or practice must be 'held' in a safe space for participants. The experience will be far

11 Journal of Practice Teaching \& Learning 7(2) 2006-07, pp.6-24. ( 2007 Whiting \& Birch Ltd 
more engaging and useful if the participants don't feel they are being blamed, tested or validated. The Tutor/Practice Teacher relationship with the student/practitioner is a powerful dynamic that needs to be acknowledged within the context of the exercise. I have found that students are open to exploring their work, but are also cautious because they know their values and issues may be challenging as well as challenged. Our occupation demands standards and codes of practice that ensure open and transparent communication. Such standards and codes expose practitioners and students across the profession to face potentially difficult moral and ethical dilemmas. The sand tray adds a dimension to reflective space that should be experienced first hand by a facilitator to help them understand the powerful dynamic that is being introduced to the reflective process.

For the purpose of preparing for the exercise I would advise that the facilitator find a trusted colleague, mentor or supervisor and work together until there is a feeling of intimate acquaintance with the sand tray. A discussion about the feelings evoked is a useful way to analyse processes. For instance, was there a temptation as a facilitator to interpret the landscape? As a person building the landscape what was it like to see it emerging? Was there anything surprising or unexpected? What would help the environment to feel comfortable? This should inspire ideas to develop a careful lesson plan. It seems to me that this expressive tool is flexible enough to be developed in many directions. I found that utilising reflection 'in' action and critically reflecting 'on' sessions using reflection models in adult education has been helpful for me in developing the sand play exercise in the class room (Schon 1987). I used Gibbs (1988) reflective cycle to analyse the group sessions I ran. The first session I facilitated was an observed teaching session as part of my Post-Graduate Certificate in Higher Education. I was able to reflect on the exercise with the observing tutor as well as receive feedback from the students. As a result of running the second session, reflection gained from student evaluation and feedback led to further adjustments in planning future sessions. I learned a great deal about the added group work dynamic that is helping me with future action and planning. I have also reflected considerably on how the exercise links into the knowledge and theory base of practice so that I can help students unpack what is going on in their landscape.

The following description of my work with the sand tray is by no means definitive and anyone considering facilitating a session should

12 Journal of Practice Teaching E Learning 7(2) 2006-07, pp.6-24. (C) 2007 Whiting E Birch Ltd 
consider undertaking further research, training and experience before practicing it with students.

\section{The sand tray and equipment}

The original sand tray methodology advises very specific measurements for a wooden box that is painted blue at the bottom. Because I am travelling with the equipment I have to improvise and use plastic gravel trays that I purchased from a local garden centre. The boxes must be water tight, quite sturdy and big enough to allow students to swirl water around and make a good sized landscape. My sand trays are $40 \mathrm{~cm} \times 20 \mathrm{~cm}$ with a depth of $5 \mathrm{cms}$. It is useful to look on the sand tray/ World Play web site where different shapes and sizes of sand trays are pictured. I provided water and play sand. I also brought a large bag of small objects, such as toy cars, small doll house dolls, worry dolls (purchased from Oxfam), toy animals, ethnic beads, small candles, old jewellery, interesting little boxes, some of which contained small mirrors, crystals, twigs, pine cones, ribbons and any other objects I think are interesting and could be used. I am always on the look out for small objects of interest and often find things at car boot sales, markets and in my children's bedrooms!! I also have a number of small houseplant shovels and forks that can be used for scoring interesting patterns in the sand which can also be moulded with fingers and hands when damp. I spread the toys and objects out on a separate table to allow students to choose easily. Each landscape can be photographed so that students have a record of their work. A digital camera may be used and the pictures then emailed to individual students following the sessions. Students can also take their own photos using mobile phones or their own cameras.

\section{The space}

A space needs to be set up that is comfortable and secure where no disturbances will occur. The group exercise is done in two's, and I have found the best way to do this is to set up a small table with a sand tray in the middle and a chair either side. For practical reasons the sand is already piled up in the tray ready to use and several jugs of water are available. Small tables for two are set up around the room arranged so that there is as little interference of each others narratives as possible.

13 Journal of Practice Teaching \& Learning 7(2) 2006-07, pp.6-24. ( 2007 Whiting \& Birch Ltd 
At the beginning of the session I have a semicircle of chairs where the group sit together so that I can introduce the exercise. When the pairings have been made the students can take their chairs to a table with a sand tray on it to begin the exercise. I pay attention to the ambience of the room, perhaps providing quiet music when students arrive, having some cushions, incense, burning oil or scented candles, if this is acceptable within fire and safety regulations. I find it helps to give students a sense of arrival in an atmosphere of calm.

\section{Setting up the exercise}

Students must know about the exercise in advance. In the cases I am describing I explained the exercise during the introductory seminar at the beginning of term and ensured the students knew date on which it would be facilitated. In introducing the exercise I explained some of the theoretical aspects of the sand tray technique and also provided some references on critical reflection and Direct Work/ Projective Play Therapy on a handout. I also explored how the technique might help in considering learning outcomes and facilitated a discussion around the acknowledgement of power relationships. I explained important logistical information, such as not arriving late or disturbing the session in any way. The session requires a commitment on the part of the student to ensure everyone has a good experience.

The main issues I have explored in sessions of sand tray work with students in placement are power and the misuse of power, anti discriminatory/ oppressive practice and empowering practice. The Learning Outcomes for the session were made explicitly to the students on a work sheet:

- Evaluate your practice using a creative visualisation tool

- Analyse your practice within the contexts of Learning Outcomes in your stage 1 placement

- Develop ideas for using creative social work tools in direct work with service users in your practice

On the day of the session the exercise was already set up when the students came into the room. It is essential that there are no disturbances so I ensured that mobile phones were switched off. During the session students must realise that even though they are working in pairs they

14 Journal of Practice Teaching \& Learning 7(2) 2006-07, pp.6-24. ( 2007 Whiting \& Birch Ltd 
are part of the supportive process for the whole group and need to respect others by engaging in their own process quietly and not creating a distraction for others. At the beginning of the session I asked students to make an agreement to work with each other respectfully. The ground rules we worked with in the session I am describing were as follows:

- Respect confidentiality

- Keep the exercise quiet and try to absorb yourself in it

- Do not chat, or get chatty

- Practice listening skills

- Support each other and stay safe

I asked the students to sit comfortably on their chair in the semi circle with their back supported and both feet on the floor, and to close their eyes. I asked them to breathe naturally and allow the out breath to relax muscles and tensions. My intention in doing this was to help the students have a sense that they are beginning a process that requires their full attention and focus. Pairs can be picked by students choosing partners themselves or by putting numbers into a bowl and pairing those with the same numbers. The pairs then go and sit at a table with a sand tray opposite each other. I asked students to decide between them who will build their landscape first and who will act as the facilitator. Each student had a work sheet containing instructions for carrying out the exercise.

\section{Carrying out the exercise}

The student facilitator asks the student opposite them to close their eyes and to think about a case that they have been working on, a scenario that has interested them within their placement, or a dynamic they would like to explore. The student facilitator then takes the student they are working with through a guided visualisation instructed in the following way on their work sheet:

'Visualise a case or situation that you are working with in your placement, one that is causing you to reflect, or that is making you feel uncomfortable, or raising issues for you. 
(Ask the partner, 'Have you chosen a case?' - allow them to nod. Don't continue till they have a case. If they can't think of a case then encourage them to think about a situation that is happening in the placement. Be flexible - encourage them to think of any situation in their placement that interests them)

Once they have settled on a scenario continue with something like the following - adapt what you are saying to support your partner's thoughts:

'Soon I am going to ask you to build a picture of your thoughts in the sand. First, I would like you to think about everything that is happening in the case/situation you are thinking of. See the service user in your mind. See all the others involved, other people and agencies. Think about how they all interact and work with this case/situation. What are the relationships between everyone? Where are you in the case? Are there any aspects that remind you of people in your own life? Do any of the people or organisations conjure up pictures of animals or objects? Start to build a scene or landscape in your mind. Imagine the case in colours, in animals, in landscapes, as if in a dream - what would it look like?

Leave a little silence then ask your partner to open their eyes and build a picture of their scene in the sand.

They can manipulate the sand and use the items on the table. You can sit with them in silence and watch as they build the picture. Make mental notes of how you feel being the listener and observer.

When the sand tray picture is complete ask your partner to explain it to you. Make some rough written notes together of your findings and feelings.

Look at the Learning Outcomes grid and make notes of any ideas that have come to you about them through the exercise.

Swap roles and start the exercise again

The exercise takes different amounts of time for different pairs of participants. I allow students to take a break at the conclusion of both scenarios which means they can leave quietly in pairs so that others can continue with their scenes. Students came back into the larger group at 
the end to discuss, evaluate and debrief the exercise. The two sessions I have so far run took two hours with around half an hour dedicated to each landscape. In the second session I took photographs of some of the landscapes. I have reflected that in future sessions I will ask students to take photographs of their landscapes with a digital camera I provide.

\section{Analysis of learning outcomes}

Since becoming an Academic Tutor my attention has focussed on the well documented dilemma of how to help students see the relevance of theory and recognise it within their practice:

A monumental challenge for many students concerns the use of theories, methods, frameworks and models in the practice setting. So often students - and indeed practitioners - will avoid theories, state they do not see their relevance, or even actively renounce them. However, theories and models guide social workers' actions and provide explanatory frameworks that make effective interventions possible and, in doing so, they contribute to ethical, evidence-based and accountable practice. (Parker, 2006, p.17)

In developing the sand tray exercise for a practice seminar group I wanted to attempt to give students the opportunity to reflect on module learning outcomes to help them begin to examine the frameworks and methodologies governing practice. Each student had a worksheet in their handouts containing a grid of placement module learning outcomes. I asked students to explore links to their reflections about the sand tray exercise with knowledge and theory identified through the practice module learning outcomes. In the feedback session with their partner I asked students to share any links to theory they identified. One student focussed on a critical incident in her placement where a long standing member of staff was consistently being overtly racist and discriminatory towards adults with severe and enduring mental health problems. Her subsequent disclosure about various incidents to her Practice Teacher caused a great deal of anxiety for her as a new practitioner in her first placement. As she and her partner explored the sand tray landscape they were able to identify ethical dilemmas and the unique position of social worker values that helped her to feel less anxious about taking

17 Journal of Practice Teaching \& Learning 7(2) 2006-07, pp.6-24. ( 2007 Whiting \& Birch Ltd 
action. I discussed the incident individually with the student and she very kindly wrote the following for inclusion in this article:

The sand tray exercise was very timely. It was the week before I was to meet with my practice teacher and the supervisor to discuss the situation and I was, quite frankly, terrified.

The exercise, and the following discussion, helped me to see the links between the theories of anti-discriminatory practice and how this works in practice and what it means. In other words, it showed me the implications and even consequences of working in an anti-discriminatory way - it is not enough to pay homage to rhetoric, but it means taking risks and sometimes taking very difficult action. It brought home to me the reality. The exercise also helped me to understand the theory behind the identity of a social worker - to me that means values, knowledge and skills that are unique to social workers. Again, I began to understand how important this identity is and that it is necessary to stand apart when service user's experiences are at stake. Theory made real. Finally, it helped me to understand that performance management, which in the past had seemed a bit ridiculous, when done properly is a very important part of practice. Reflection is the most important part of social work, and the sand tray exercise, which appeared to be a bit of fun and an experiment, proved to be an exceptional tool for good reflection to take place.

This student had been concerned about the outcome of taking action when she perceived her position as powerless when measured against that of an experienced member of staff from whom she was supposed to be learning. In fact the student describes a feeling of being 'terrified'. In her article beginning with the words, 'It's not that I'm no good it's just that I'm scared ...' Howath (1999) discusses the importance of managing anxiety effectively in practice learning to facilitate 'functional learning cycles'. The student's confidence seemed boosted by the sand tray exercise and she recognised the importance of challenging racism and anti discriminatory practice through channels designed to protect workers and people who use services. The student had a supportive Practice Teacher who stood beside her through an active process of investigating the incidents, another important link in developing robust professionalism.

Other students built case studies in the sand and discussed how powerful it was in their feedback to the group. As I watched the sand tray landscapes emerge in the sessions they appeared to portray signs

18 Journal of Practice Teaching \& Learning 7(2) 2006-07, pp.6-24. (C) 2007 Whiting \& Birch Ltd 
of powerlessness and hopelessness. I observed islands, walls of sand, figures hidden behind hills or cut off. Conversely, what followed in the feedback of narratives were mostly feelings of hope and understanding; ideas about solutions and future action. Here is realised the importance of non-interpretive intervention, the inherent rule of projective play therapy. In the moment of intuitive creation, lies the revelations, the potential solutions, the ways forward, the human condition of optimism and surety of finding a way through. Over the two sessions I ran with two different sets of students I heard them discussing parenting and child protection, family systems, working within the health sector, organisational structures, social justice and some of the conflicts between the humanistic values in social work and the modernisation agenda. Students fed back that they saw the potential of using the sand tray as a Direct Work tool. Further, many students demonstrated that they were already beginning to develop a sense of the importance of examining personal values and the part they play in promoting social justice and ethical professional practice. This was good learning for me as I reflected on the motivation that exists for people who wish to become social workers and their intentions to promote the best interests of people they work with.

\section{Evaluations and feedback}

Immediate feedback from both sessions demonstrated that students felt they had undertaken a powerful exercise that had deepened their knowledge of their work. Two students described how they removed the sand tray from their desks and went and sat on the floor, giving them a real sense of play. Other students agreed they enjoyed the playful aspects of the exercise and using creativity to think about their cases. Some students said they had come with an open mind, or a certain amount of scepticism. The following are some comments from the evaluation sheets which were completed by all 10 students at the second session:

It made me look. Good to see how I placed myself within the situation.

It helped me see my case outside of my head i.e. distance myself temporarily and be objective........good exercise - exceeded my expectations.

19 Journal of Practice Teaching \& Learning 7(2) 2006-07, pp.6-24. @ 2007 Whiting \& Birch Ltd 
I saw how useful this tool is. Feel it would be appropriate to use it with service users.

Great exercise. Open to individual interpretation.

I went into the session very open minded and was impressed with how powerful the session was.

Very interested, very sceptical before the session however, this changed as I found it very useful to visualise the case scenario in depth.

A good vehicle for discussing difficult cases.

Something in uni that's fun at last!

About half the group said that the exercise had helped them reflect on learning outcomes, others said they were more interested in seeing the landscape and how it might help them in their practice. Comments on the evaluation sheets about links with module learning outcomes varied:

Not many outcomes linked to my scene but useful to reflect on them.

Helpful to link the session to learning outcomes.

....struggled relating it to context and practices learning outcomes

I really enjoyed this session; it was useful, helped greatly with the learning outcomes and gave me some good ideas.

I got out of this what I needed and asked for i.e. linked practice to learning outcomes.

This article has been very upbeat and positive about the learning opportunities offered by the sand tray exercise. However, I am more than aware that some of my group tend to avoid small group sessions and I have a sense of an 'opt out' element. Howath's (1999) discussion of dysfunctional and functional learning cycles is of relevance here in establishing what motivates students and what might be 'scaring them

20 Journal of Practice Teaching \& Learning 7(2) 2006-07, pp.6-24. ( 2007 Whiting \& Birch Ltd 
off'. I might also add that seminars appear to have a 'bolt on' rather than 'integral' feel with issues including being timetabled on a Friday and being held at very irregular intervals throughout the course. Seminars may appear to students to add a further burden to an already full timetable.

I have duly noted that many of students who did come to the session expressed some scepticism about the usefulness of the exercise, perhaps they were also understandably anxious about a tool which may ask them to confront the more emotional and difficult aspects of the social work task. In the first session a student asked if the exercise was a psychological test and I needed to reassure him. He was very nervous about taking on the role of facilitator with the other student. The student gave very positive feedback on learning at the end of the session. My hope is that 'word of mouth' and this article may provide encouragement. I will need to do more research on student motivation.

Reflecting on the exercise has become an important aspect of my own practice in delivering this session, as well as deepening my knowledge about what students may need in their learning to practice reflectivity. I have for example recognised the significance of being a motivator, innovator and leader in adult education to help students get the very best out of learning. In the sand tray exercise, being a 'teacher' requires a process of letting go of traditional 'teaching roles' and finding ways to hand learning over to students. My reflections on both sessions were that the crucial elements of my work were in setting the scene for an exercise that belonged to the group. I saw my role as holding the space, answering any questions and ensuring the space was respected, which it was without my help. My action for the next session is to ensure I ask students how they see my role while the exercise is being carried out. Do they want me to remain in the room, do they want me to wander about and observe, would they prefer me to sit in a corner only helping them when they ask for it?

\section{Conclusion}

The success of the sand tray exercise lies in its value as an intuitive and expressive tool that can be used therapeutically across a range of settings to promote an understanding of our place in 'all this'. The sand tray is a

21 Journal of Practice Teaching \& Learning 7(2) 2006-07, pp.6-24. ( 2007 Whiting \& Birch Ltd 
tool for focussing on what is going on and provides a space to potentially resolve, or solve difficulties or make links for ourselves. Sand Play is a projective play process developed by Lowenfeld outside of the traditional psychodynamic techniques traditionally used in psychoanalysis. Thus projective play allows the process to belong to the maker and honours their narrative of it. Projective play techniques have transferred to use with adults through the growth of Jungian and Gestalt Therapy. The sand tray exercise is experienced first hand by the student/practitioner so they too can come to understand the intrinsic value of 'self' within a process. Having experienced the tool as a Direct Worker with children and as a Practice Teacher I saw its potential as a small group teaching tool. I developed a sand tray session that I hoped would allow students to examine an intuitively made landscape about their practice and link it to a knowledge and value base as well as learning outcomes. Immediate feedback and evaluation with students indicates that there was some success at linking theory, practice and learning outcomes. The exercise has also shown itself to be a rich source of learning for student/practitioners, many of whom were sceptical about its value. The feedback has inspired me to go on developing the sand tray tool to help students reflect on practice.

The development of reflective practice in Higher Education has demonstrated the benefits that can be derived from deep learning processes. In social work the complexity of relationships between practitioner, student, professions and organisations with service users requires a thorough approach in examining practice values that empower as well as uphold human dignity and social justice. Yet opening up practice to scrutiny comes with potential anxieties for students and practitioners about the very frameworks designed to uphold transparent practice to deliver services. Reflective practices have to be developed that allow practitioner/students to safely explore values, belief systems and self knowledge. Students also need to examine learning processes connected to knowledge. In beginning to develop the sand tray seminar it is my hope that this is a tool will contribute to innovative practice in reflective processes in social work education. 


\section{References}

Brockbank, A. and MacGill, I. (2000) Facilitating Reflective Learning in Higher Education Buckingham: Open University Press

De Domenico, G. (1995) Sand Tray-World Play/a comprehensive guide to the use of the sand tray in psychotherapeutic and transformational settings. Oakland, Ca: Vision Quest Images (accessed at http://vision-quest.us/VQISR/SandtrayWorldplay_The\%20Tool_.pdf)

De Domenico, G. (2002) Sandtray-WorldplayTM: A Psychotherapeutic and transformational Sandplay Technique for Individuals, Couples, Families and Groups The Sandtray Network Journal [accessed at www.sandtray. org/publications page, or direct access at http://vision-quest.us/vqisr/ The\%20Sandtray-Worldplay\%20Method\%20of\%20Sandplay.pdf]

General Social Care Council (2006). Assuring Quality for Child Care Social Work. London: GSCC

Gibbs, G. (1985) Teaching Students to Learn. Buckingham: Open University Press

Gibbs, G. (1988) Learning by Doing. A guide to teaching and learning methods. Oxford: Oxford Polytechnic

Gould, N. and Baldwin, M (Eds.) 2004. Social Work, Critical Reflection and the Learning Organisation. Aldershot:Ashgate

Howath, J. (1999) It's not that I'm no good it's just that I'm scared: Managing anxiety associated with practice learning. Issues in Social Work Education, $19,1,17-35$

Kolb, D.A. (1984) Experiential Learning. Englewood Cliffs, NJ. Prentice Hall

Lowenfeld, M. (1967) Play in childhood. New York: Wiley (accessed at http://www. sandtray.com/history.htm)

Oaklander, V. (1978) Windows to Our Children. Highland, NY: The Gestalt Journal Press

Parker, J. (2006) Effective Practice Learning in Social Work. Exeter: Learning Matters

Schon, D.A. (1987). Educating the Reflective Practitioner San Francisco: JosseyBass

Stevens, C. (2004) Playing in the sand The British Gestalt Journal, 13, 1, 18-23

Taylor, C. (2006) Narrating the significant experience: Reflective accounts and the production of (self) knowledge. British Journal of Social Work, 36, 189-206

Yip, K. 2006 Self reflection in reflective practice: a note of caution.. British Journal of Social Work, 36, 777-788

23 Journal of Practice Teaching \& Learning 7 (2) 2006-07, pp.6-24. @ 2007 Whiting \& Birch Ltd 


\section{Web Site References}

All website addresses were accessed and available on $15^{\text {th }}$ Oct 2007 http://www.calplaytherapy.org/trainings.html

http://vision-quest.us/vqisr/The\%20Sandtray-Worldplay\%20Method\%20of\%20S andplay.pdf. Based on Sand tray Network Journal, (2002), 6, 1

http://www.mappmed.co.uk/Workshops/SandPlayTherapy/PlayingintheSandPubli shedPaper/tabid/59/Default.aspx (Christine Stevens article - see References above)

24 Journal of Practice Teaching E Learning 7(2) 2006-07, pp.6-24. (C) 2007 Whiting E Birch Ltd 